\title{
16. RACEMIZATION OF ISOLEUCINE IN FORAMINIFER TESTS FROM LEG 42A, SITES 372 AND 376
}

\author{
Jeffrey L. Bada,1 Scripps Institution of Oceanography, University of California, San Diego, La Jolla, \\ California \\ Eugene H. Man, Department of Chemistry, University of Miami, Coral Gables, Florida \\ Barry J. Katz, Rosenstiel School of Marine and Atmospheric Sciences, University of Miami, Miami, Florida \\ and \\ Kenneth J. Hsü, Eidg. Technische Hochschule Zürich, Geologisches Institüt, Zürich, Switzerland
}

\section{INTRODUCTION}

During the last few years, several studies have shown that under certain conditions the amino acid racemization reaction can be used to estimate the age of fossil materials and also to deduce paleotemperatures (see Bada and Schroeder, 1975; and Schroeder and Bada, 1976, for reviews). Since racemization is a chemical reaction, there are two variables which can affect the extent of racemization in a fossil, time and temperature. If the temperature history of a fossil can be evaluated, then the extent of racemization in that fossil can be used to estimate its age, or, alternatively, if the age can be estimated using some other dating technique, then the extent of racemization can be used to estimate the average temperature to which the fossil has been exposed during its depositional history.

All of the samples which have been used so far in studies of amino acid racemization in marine sediments have come from ocean areas where bottom water temperatures have probably been fairly constant over the last several million years (Savin et al., 1975). In certain oceanic areas, however, bottom water temperatures may not have been constant throughout the past, and the fluctuations in temperature may, in turn, be detectable by amino acid racemization, provided the age of the sample can be estimated, using some other independent dating method. In this instance, the amino acid racemization reaction is used as a paleothermometer. An example of this application is provided by the results presented here for Leg $42 \mathrm{~A}$, Sites 372 and 376 . Site 372 was located southeast of Menorca in the Western Mediterranean, whereas Site 376 was west of Cyprus in the east (see Hsü et al., this volume).

\section{EXPERIMENTAL METHODOLOGY}

The experimental procedure is essentially the same as that described in earlier publications (Bada and Man, 1973; Bada et al., 1977). All reagents were carefully purified to remove traces of contamination. Deionized water was doubly distilled in an all-glass apparatus. Constant boiling $6 \mathrm{M} \mathrm{HC1}$ was prepared by two successive azeotropic distillations of reagent-grade

\footnotetext{
${ }^{1}$ Alfred P. Sloan Fellow 1975-1977.
}

HC1. Ammonium hydroxide was prepared by dissolving gaseous ammonium in doubly distilled water on a vacuum line under reduced pressure. All glassware was cleaned with Chromerge (potassium dichromate-concentrated sulfuric acid) and washed extensively with deionized water, followed by numerous washings in doubly distilled water.

Approximatey $10 \mathrm{~g}$ of sediment was slurried in several hundred $\mathrm{ml}$ of doubly distilled water and then carefully poured onto a clean stainless steel sieve ( $\sim 62$ $\mu \mathrm{m})$. The collected foraminifers were carefully washed in doubly distilled water, transferred to clean Pyrex beakers, and subjected to several 5 to 10 minute periods of ultrasonic cleaning in order to remove any clay particles or organic material which might be absorbed onto the surface of the foraminifer tests (Schroeder, 1975). After the ultrasonic cleaning, the foraminifer tests were dissolved in an excess of $6 M$ $\mathrm{HCl}$ and this solution was hydrolyzed for 24 hours in a sealed glass tube at $100^{\circ} \mathrm{C}$. Following hydrolysis, the sample was desalted, as described elsewhere, using BIORAD AG-50W-X8 cation exchange resin.

Amino acid analyses were carried out on a Beckman-Spinco Model 118 Automatic Amino Acid Analyzer.

\section{RESULTS AND DISCUSSION}

The ratios of alloisoleucine (allo) to isoleucine (iso) determined in foraminifer tests from Sites 372 and 376 and the ages of these samples deduced from the calcareous nannofossil assemblages are shown in Table 1. These results, plotted in the form of the reversible first-order kinetics racemization ${ }^{2}$ equation are shown in Figure 1 (see Bada and Schroeder, 1972, and Schroeder and Bada, 1976, for a discussion of isoleucine racemization kinetics).

The present bottom water temperature in the Mediterranean is $\sim 13^{\circ} \mathrm{C}$ and the racemization kinetic curve estimated at this temperature is shown in Figure 1. It is readily apparent that the observed extent of isoleucine racemization in the samples from Sites 372 and 376 is considerably less than that which would be predicted

2 Actually, the reaction involving isoleucine is more properly termed epimerization, but for simplicity we will refer to it here as racemization. 
TABLE 1

Isoleucine Racemization in Foraminifer Tests From Sites 372 and 376 (Calcareous Nannoplankton Zones given in Müller, this Volume)

\begin{tabular}{llll}
\hline $\begin{array}{c}\text { Sample } \\
\text { (Interval } \\
\text { in } \mathrm{cm})\end{array}$ & $\begin{array}{c}\text { Calcareous } \\
\text { Nannoplankton } \\
\text { Zone }\end{array}$ & $\sim_{\text {Age }(\mathrm{yr})^{\mathrm{a}}}$ & Allo/iso \\
\hline $372-2-2,23-25$ & NN 18-NN 16 & $1.8-2.9 \times 10^{6}$ & 0.962 \\
$372-3-3,41-44$ & top of NN 14 (?) & $3.3 \times 10^{6}$ & 1.016 \\
$376-5-1,83-85$ & NN 19 & $1.0-1.8 \times 10^{6}$ & 0.610 \\
\hline \multicolumn{4}{l}{$\begin{array}{l}\text { a Estimated from correlations of nannoplankton zones with pal- } \\
\text { eomagnetic reversals (Ryan, 1973). }\end{array}$}
\end{tabular}

using a temperature of $13^{\circ} \mathrm{C}$. The racemization results imply that the actual temperatures to which the Site 372 and 376 samples have been exposed since their deposition have been considerably cooler than the present-day value of $13^{\circ} \mathrm{C}$. This result, in fact, is consistent with various lines of evidence which suggest that $\sim 5$ million years ago the bottom water temperature in the Mediterranean was considerably cooler than it is at present.

At the beginning of the Pliocene, when the desiccated Mediterranean was again flooded by marine waters, the Strait of Gibraltar was probably deeper then the present 400-meter depth (Hsü et al., 1973; Hsü et al., this volume). Paleoecological and sedimentological evidence suggest that deep and cold Atlantic waters did enter the Gibraltar during the early Pliocene (Cita, 1973). The occurrence of psychrospheric ostracodes in the Western Mediterranean (at Leg 13 Site 132) indicates a Pliocene bottom temperature in the range of $4^{\circ}$ to $6^{\circ} \mathrm{C}$ (Benson, 1973). The earliest Pliocene benthic foraminifers are species found typically in a basin with a sill-depth of about 1200 meters (Wright, this volume) and this conclusion is in complete agreement with that based upon the study of ostracodes. Cold-water species of ostracodes are present in the upper Pliocene, but are absent in the Quaternary, at Site 132 (Benson, this volume); the bottom temperature must have warmed up to about $10^{\circ} \mathrm{C} 1.5$ to 2.0 million years ago, when the psychrospheric species disappeared from the Western Mediterranean.

We can entertain two alternative models for the history of bottom-water temperature in the Mediterranean. One suggests that the bottom-water temperature 5 million years ago was about $4^{\circ} \mathrm{C}$, and the temperature then warmed up at a constant rate of about $2^{\circ} \mathrm{C}$ per million years. If this model is correct, the average temperature to which the samples from Sites 372 and 376 have been exposed should be approximately equal to the mean of the initial and final temperatures, or about $9^{\circ} \mathrm{C}$. Using the racemization curves estimated at various temperatures, we found that a temperature of $5^{\circ}$ to $6^{\circ} \mathrm{C}$ best fit the racemization results obtained for Sites 372 and 376 . The racemization curves estimated at $5^{\circ}$ to $6^{\circ} \mathrm{C}$ are shown in Figure 1 . The racemizationdeduced temperature is less than that which is predicted using the model where temperature has increased at a constant rate.
A second model suggests that the temperature 5 million years ago was about $4{ }^{\circ} \mathrm{C}$ and since that time the temperature has increased exponentially to the present-day value of $13^{\circ} \mathrm{C}$. The racemization-derived average temperature appears to be more compatible with the model in which the bottom water temperatures have increased exponentially. However, in view of the few samples analyzed and of the uncertainties in the temperature deduced from amino acid racemization, we cannot rule out other more sophisticated models, such as one which postulates a linear temperature increase during the Pliocene and an oscillating temperature change during the Pleistocene. Nevertheless, the racemization results do provide additional, independent evidence that during the last several million years the bottom water temperatures in both the Western and Eastern Mediterranean have been considerably cooler than they are presently.

\section{CONCLUSION}

The results we have presented here suggest that amino acid racemization might be used to deduce temperatures in oceanic areas where bottom water temperatures may have varied throughout the past. In the case discussed here, the amino acid racemization results provide additional evidence that bottom water temperatures in the Mediterranean have been considerably cooler than they are at present. Another important potential application of this racemization paleotemperature technique would be to investigate possible fluctuations in bottom water temperatures in nearshore basins during the Pleistocene ice ages.

\section{ACKNOWLEDGMENTS}

We thank E. Peltzer for helpful comments. This work was supported by NSF Grant DES74-12075, DES75-20937.

\section{REFERENCES}

Bada, J. L. and Man, E. H., 1973. Racemization of isoleucine in cores from Leg 15, Site 148. In Heezen, B. C., MacGregor, I. D., et al., Initial Reports of the Deep Sea Drilling Project, Volume 20: Washington (U. S. Government Printing Office), p. 947-951.

Bada, J. L., Man, E. H., and Walker, A. C., 1977. Racemization of isoleucine in Leg 37, Site 332 and 333 cores. In Aumento, F., Melson, W. G., et al., Initial Reports of the Deep Sea Drilling Project, Volume 37: Washington (U. S. Government Printing Office), p. 633-636.

Bada, J. L. and Schroeder, R. A., 1972. Racemization of isoluecine in calcareous marine sediments: Kinetics and mechanism: Earth Planet. Sci. Lett., v. 15., p. 1.

1975. Amino acid racemization reactions and their geochemical implications: Naturwissenschaften, v. 62 , p. 71.

Benson, R., 1973, Psychrospheric and continental ostracoda from ancient sediments in the floor of the Mediterranean. In Ryan, W. B. F., Hsü, K. J., et al., Initial Reports of the Deep Sea Drilling Project, Volume 13: Washington (U. S. Government Printing Office), p. 1002-1009.

Cita, M. B. A., 1973. Mediterranean Evaporite: paleontological arguments for a deep-basin desiccation model. In 


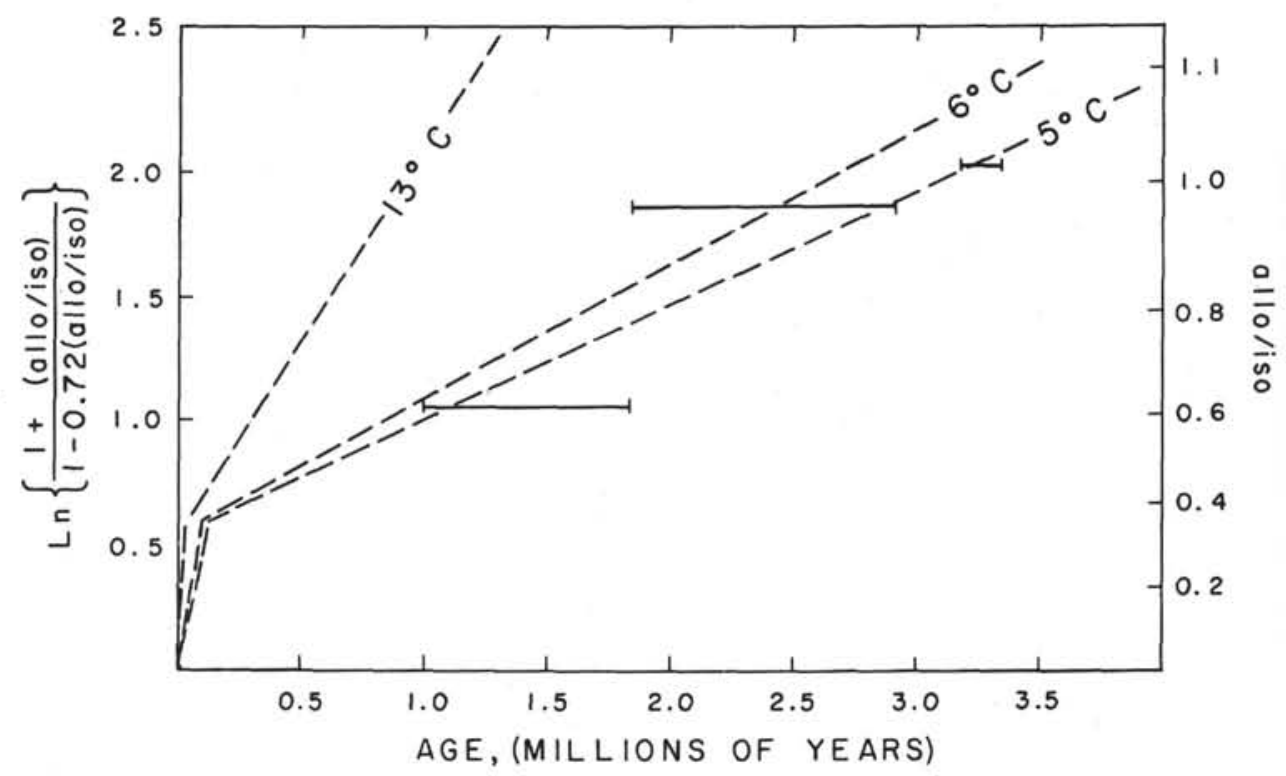

Figure 1. Isoleucine racemization in foraminifer tests from Leg 42A, Sites 372 and 376, and the estimated racemization kinetic curves at $5^{\circ} \mathrm{C}, 6^{\circ} \mathrm{C}$, and $13^{\circ} \mathrm{C}$. The kinetic curves at the various temperatures were calculated by dividing the racemization kinetics into two linear segments. The first linear region extends from an allo/iso ratio of 0.0 to $\sim 0.35$; the second linear region begins at allo/iso $\simeq 0.35$ and continues to equilibrium (i.e., allo/iso $\simeq 1.3-1.4$ ). The slope (which equals $1.72 \cdot k_{i s o}$ ) of the first linear segment of the racemization curve is $\sim 10$ times that of the second linear portion (Bada and Schroeder, 1975). The values of $k_{i s o}$ for the first linear region at the various temperatures were determined from the equation (Bada and Schroeder, 1972) Log $k_{i s o}=$ $15.77-5939 / T$, where $T$ is in ${ }^{\circ} \mathrm{K}$. A similar procedure for calculating racemization kinetic curves at various temperatures has been used by Wehmiller et al. (1976).

Drooger, C. W., et al. (Eds.), Messinain Events in the Mediterranean: Amsterdam (North Holland Publ. Co.), p. 206-228.

Hsü, K. J., Cita, M. B., and Ryan, W. B. F., 1973. The origin of the Mediterranean Evaporites, In Ryan, W. B. F., Hsü, K. J., et al., Initial Reports of the Deep Sea Drilling Project, Volume 13: Washington (U. S. Government Printing Office), p. 1023-1231.

Ryan, W. B. F., 1973. Paleomagnetic stratigraphy. In Ryan, W. B. F., Hsü, K. J., et al., Initial Reports of the Deep Sea Drilling Project, Volume 13: Washington (U. S. Government Printing Office), p. 1380-1386.

Savin, S. M., Douglas, R. G. and Stehli, F. G., 1975. Tertiary marine paleotemperatures: Geol. Soc. Am. Bull, v. 86, p. 1499.
Schroeder, R. A., 1975. Absence of $\beta$-alanine and $\gamma$-aminobutyric acid in cleaned foraminiferal shells: Implications for use as a chemical criterion to indicate removal of nonindigenous amono acid contaminants: Earth Planet Sci. Lett., v. 25 , p. 274.

Schroeder, R. A. and Bada, J. L., 1976. A review of the geochemical applications of the amino acid racemization reaction: Earth Sci. Rev., v. 12, p. 347.

Wehmiller, J. F., Hare, P. E., and Kujala, G. A., 1976. Amino acids in fossil corals: Racemization (epimerization) reactions and their implications for diagenetic models and geochronological studies: Geochim. Cosmochim. Acta, v. 40, p. 763. 